\title{
Assessment of Functional Outcome in Distal End Radius Fractures Managed with Locking Plates
}

\author{
Jairam Jagiasi' ${ }^{1}$ Ali Saify², Ankit Prasad ${ }^{3}$, Amit Joshi $^{3}$, Vivek Dubey², Rajnikant Patel² \\ 1Professor \& HOD, 2Junior Resident, ${ }^{3}$ Senior Resident, Department of Orthopedics, \\ Hinduhridaysamrat Balasaheb Thackeray Medical College and Dr RN Cooper hospital, Mumbai, Maharastra, India.
}

\begin{abstract}
Aim: Present study was conducted to determine the functional outcome of operative treatment of distal radial fractures with volar locking plate system in a tertiary teaching hospital. Twenty five patients were included into the study between July 2015 to January 2016.

Methodology: There were 14 males and 11 females, with a mean age of 49 . A total of 18 patients had fractures in dominant upper limb. $24 \%$ (6) of the fractures were type $A$, $12 \%$ (3) were type $B$, and $64 \%(16)$ were type $C$. They were regularly followed up. Assessment of pain, range of motion and standard radiographs were performed. The Gartland and Werley functional scores were recorded.

Result: The radiographic results at the final follow-up showed a mean of $17^{\circ}$ of radial inclination, $2.5-\mathrm{mm}$ radial shortening, and mean volar tilt of $3.4^{\circ}$ and none of them had an articular step $>2 \mathrm{~mm}$. An excellent or good result was obtained in 23 (92 $\%$ ) patients according to the Gartland and Werley score. Overall internal fixation of distal radial fractures with a locking
\end{abstract}

\section{INTRODUCTION}

Distal radius fractures have an approximate incidence of 1:10,000 people and represent $16 \%$ of all fractures and $74 \%$ of forearm fractures managed by orthopaedic surgeons. ${ }^{1}$ Distal radius fractures account for up to $20 \%$ of all fractures treated in emergency departments. ${ }^{2}$ The management of distal radius has undergone extraordinary evolution over two centuries since Colle's proclamation in 1814, from universal cast treatment to pinning to bridging external fixator to buttress plating to dorsal locking plates to advanced palmer locking plates \& column specific plating. Distal radial fractures have a bimodal age distribution, consisting of a younger group who sustains relatively high-energy trauma to the upper extremity and an elderly group who sustains both high-energy injuries and insufficiency fractures. ${ }^{2}$ Bartosh and Saldana $(1990)^{3}$ believe that when close reduction is performed, the thicker palmer ligaments are brought out to length and pull on the distal fragment before the thinner dorsal ligaments exert any traction. The dorsal ligaments are oriented in a relative " $Z$ " orientation, which allows them to lengthen with less force than the more vertically oriented palmer ligaments. plate system provided a stable fixation with good clinical outcomes for patients with unstable distal end radius fractures.

Keywords: Functional Outcome, Locking Plates, Radius Fractures.

\section{*Correspondence to:}

\section{Dr. Ali Saify}

Room No-407, RMO quarter,

Dr. R.N. Cooper Municipal General Hospital, Juhu, Mumbai, Maharastra, India.

\section{Article History:}

Received: 21-08-2016, Revised: 07-09-2016, Accepted: 10-09-2016

\begin{tabular}{|l|c|}
\hline \multicolumn{2}{|c|}{ Access this article online } \\
\hline $\begin{array}{l}\text { Website: } \\
\text { www.jjmrp.com }\end{array}$ & \\
\hline DOI: & \\
10.21276/jick Response code \\
\hline
\end{tabular}

This limits the ability of any technique of closed traction reduction to accurately restore palmer tilt. Rikkli et al $(1996)^{4}$ interpreted the wrist as consisting of three distinct columns, each of which is subjected to different forces.

This theory emphasizes that:

(1) the lateral, or radial, column is an osseous buttress for the carpus and is an attachment point for the intracapsular ligaments;

(2) the intermediate column functions in primary load transmission and may be considered the cornerstone of the radius because it is critical for both articular congruity and distal radioulnar function; and

(3) the medial, or ulnar, column serves as an axis for forearm and wrist rotation as well as a post for secondary load transmission.

\section{Classification}

The most detailed classification, to date, is the AO system, which is organized in order of increasing severity of the osseous and articular lesions. The classification divides these fractures into extra-articular (Type A), partial articular (Type B) and complete articular (Type C). ${ }^{5}$ (Fig 1) 


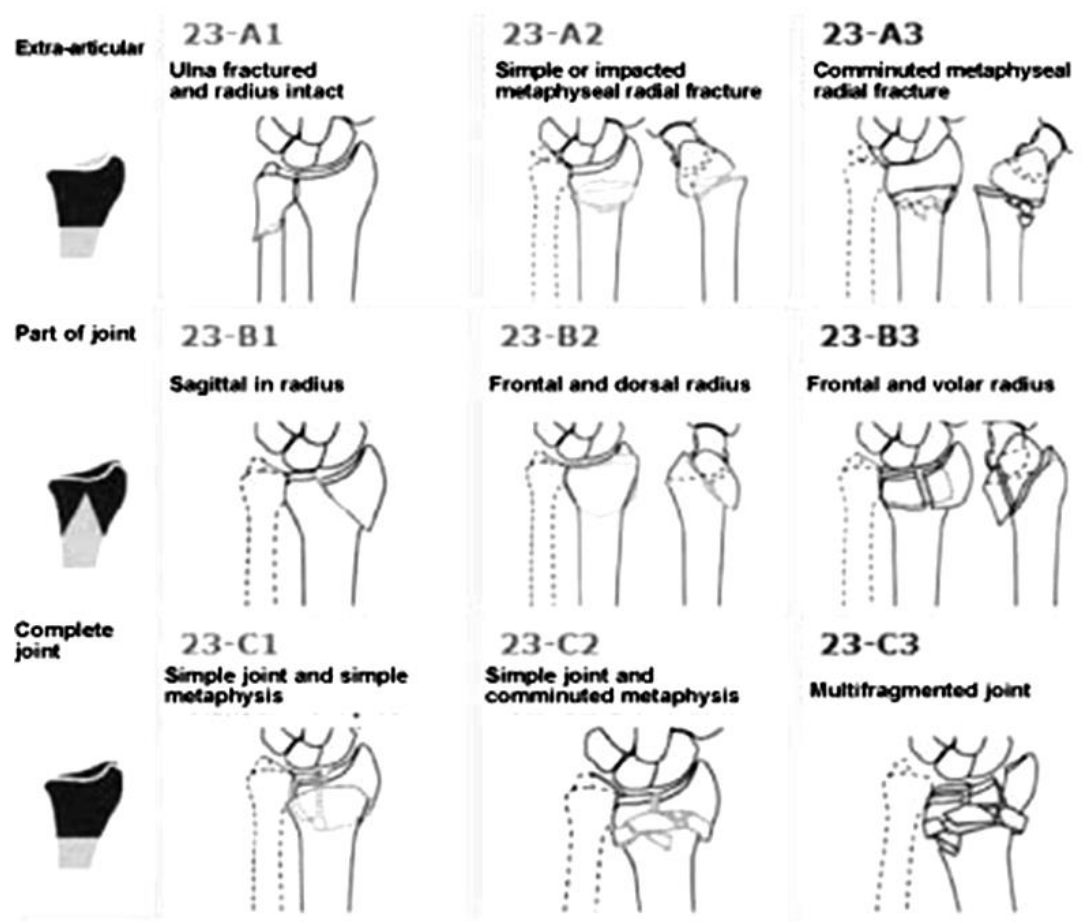

Fig 1: AO Classification for the fractures of distal radius. ${ }^{5}$

Radiographic signs that alert the surgeon, that the fracture is probably unstable and closed reduction alone will be insufficient include the following. ${ }^{6}$
a) Dorsal comminution greater than $50 \%$ of the width laterally
b) Palmar metaphyseal comminution
c) Initial dorsal tilt greater than 20 degrees
d) Initial displacement (fragment translation) greater than $1 \mathrm{~cm}$
e) Initial radial shortening more than $5 \mathrm{~mm}$
f) Intra-articular disruption
g) Associated ulna fracture
h) Severe osteoporosis

Surgical treatment (plating in particular) ensures more consistent correction of displacement and maintenance of reduction. The choice of surgical technique for reduction and fixation depends on fracture displacement, joint surface involvement, patient age, bone quality, handedness, occupation, and avocation. Surgeon experience and preference also dictates the treatment method. Paul A. Martineau et al. ${ }^{7}$ documented that, the locking nature of the screw-plate construct produces fixation even in bone defects and osteopenic bone and permits early range of motion exercises. In contrast to external fixation and percutaneous pinning, no tethering of muscle, tendon, or capsule occurs with plate fixation and therefore motion of the wrist and fingers is uninhibited. These advantages would permit earlier and more aggressive rehabilitation and more rapid regain of function.

\section{METHODOLOGY}

Our study design was a prospective study. 25 Patients with acute Distal end Radius Fractures were treated by DER Locking plates were recruited and studied. Radiological and clinical assessments were made at 3 and 6 months. Of the 25 patients, 14 were men and 11 were women, with a mean age of 49 years (range, 2072 years). The majority of the patients (23 out of 25 ) were righthand dominant. According to the Müller-AO comprehensive classification, $24 \%$ (6) of the fractures were type A, $12 \%$ (3) were type $B$, and $64 \%$ (16) were type C. Associated ulnar injuries were involved in 6 patients all of them were at ulnar styloid fractures, 4 of the patients had associated fractures (Hip, contra lateral humerus contra lateral forearm, ribs) There were no open fractures.(Fig 2,3)

Inclusion Criteria

For patients in the present study were listed as follows:

- Patients must be over eighteen years old (after skeletal maturity), of either sex;

- Patients suffered from acute Distal End Radius Fractures

- Patients were treated by Distal end radius locking plates

- Postoperative follow up at 3 months and 6 months was available

- Patients should not have any previous upper limb pathology with restriction of range of motion

\section{Exclusion Criteria}

For patients in the present study were listed as follows:

- Patients refusing to take the examinations,

- Patients lost to follow up,

- Patients with pre-existing upper limb problems.

- Patients with implant failure (periprosthetic fractures, breakage of implant)

\section{Operative Details}

The time from injury to surgery ranged from 6 to 32 days, $A$ standard volar approach over the flexor carpi radialis (FCR) tendon was used with the interval of dissection between the FCR and the radial artery.(Fig 4) The pronator quadratus was lifted from the radial border, and the muscle was retracted ulnarly. The volar aspect of the distal radius and the fracture were identified. In 1 case intaoperatively distal radio-ulnar joint (DRUJ) instability was found which was fixed through a percutaneous $k$ wire passed through radial styloid and then ulna in supine position. The locking plate system used in this study. We used a combination of the juxta-articular volar plates, which are pre-contoured to support the radial and intermediate columns. All procedures were performed by the senior Faculty or under their supervision. (Fig 5) 


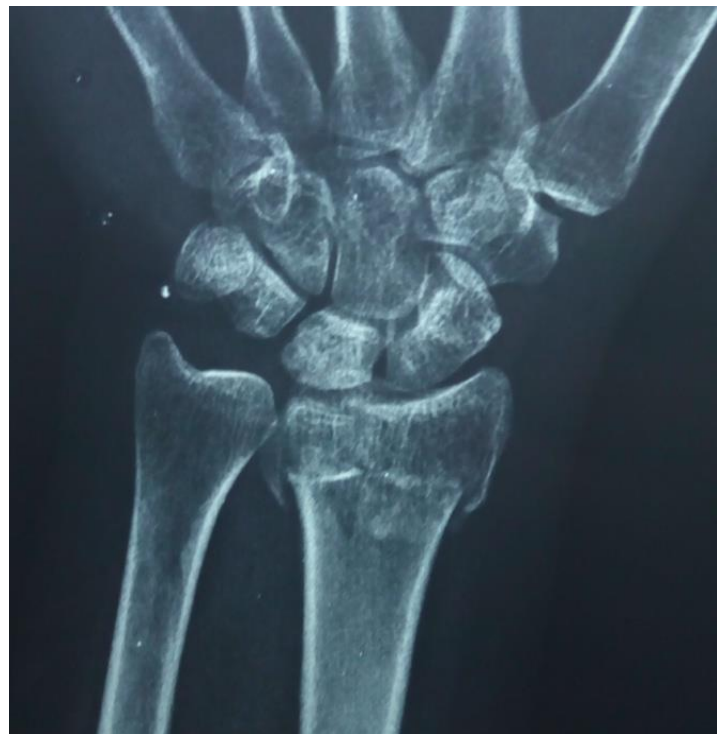

Fig 2: Preoperative anteroposterior radiograph of left wrist showing distal radius fracture type $C$ in a 32 year, male with a history of road traffic accident.

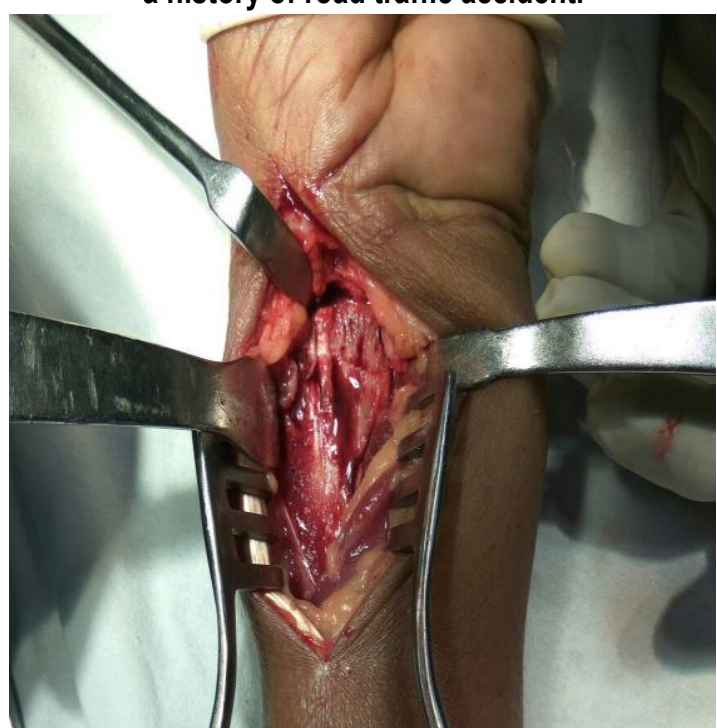

Fig 4: Showing interval of dissection formed between brachioradialis radially and flexor carpi radialis medially, Radial artery is retracted medially.

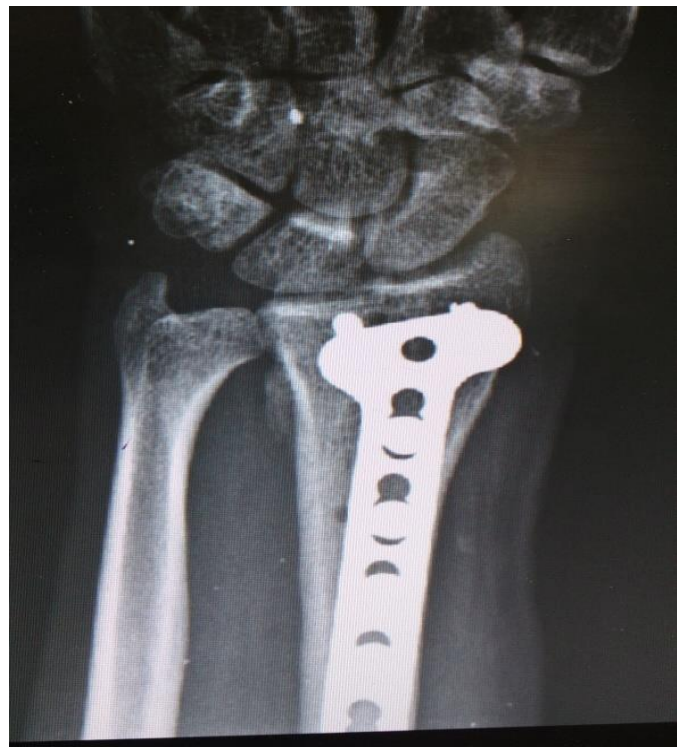

Fig $6: 6$ months Postoperative antero posterior radiograph of left wrist of a 32 year, male showing type $C$ distal radius fracture fixed with distal radius locking plate

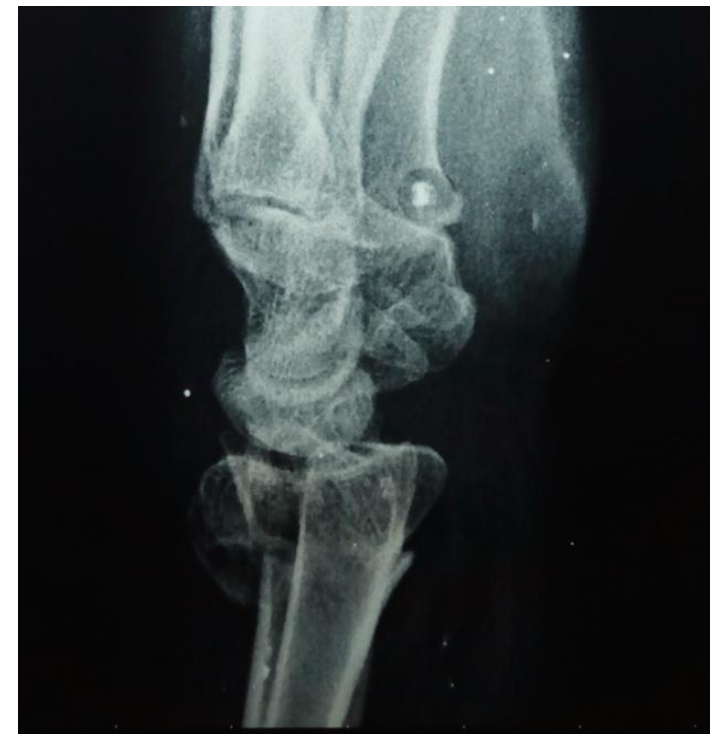

Fig 3: Preoperative lateral radiograph of left wrist showing distal radius fracture type $C$ in a 32 year, male with a history of road traffic accident.

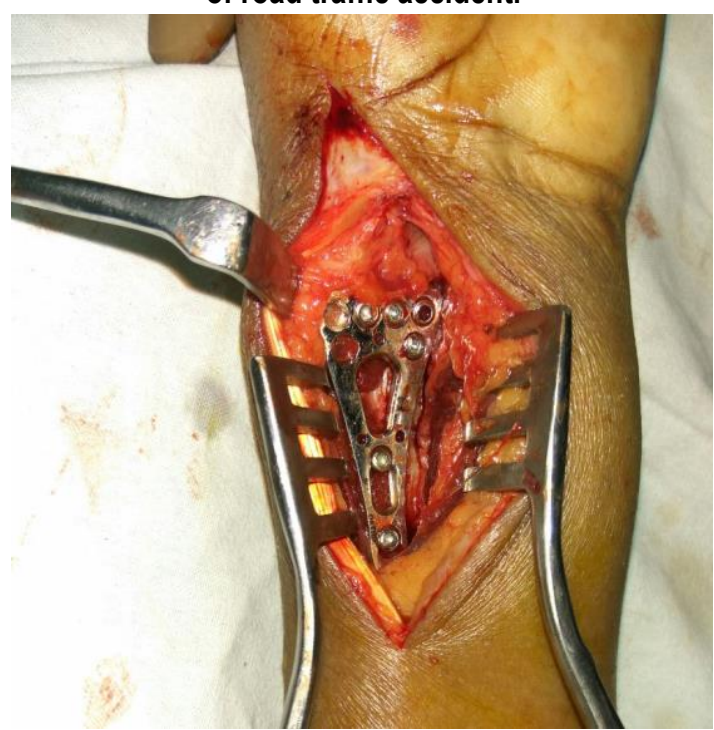

Fig 5: Showing Placement of volar distal radius locking plate on the volar aspect of the radius.

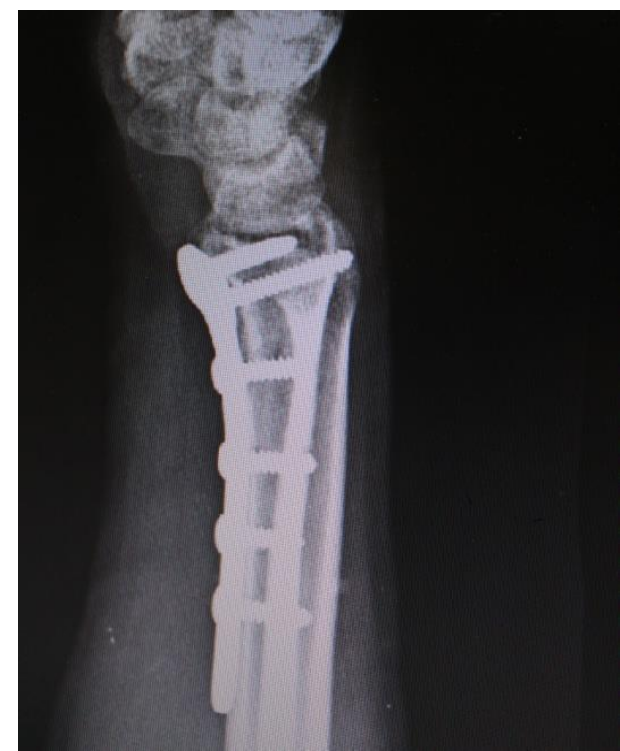

Fig 7: 6 months Postoperative Lateral radiograph of left wrist of a 32 year, male showing type $\mathrm{C}$ distal radius fracture fixed with distal radius locking plate. 


\section{Radiological Evaluation}

Post-operative postero-anterior and lateral radiographs were taken during each visit. Measurements were recorded according to the criteria defined by Kreder et al. ${ }^{8}$ On the postero-anterior film, the radial length, radial angle, articular step-off and gap were measured. On the lateral film, the palmar tilt angle and articular step-off and gap were measured. Union of fracture was defined as trabecular bridging across the fracture site. (Fig 6,7)
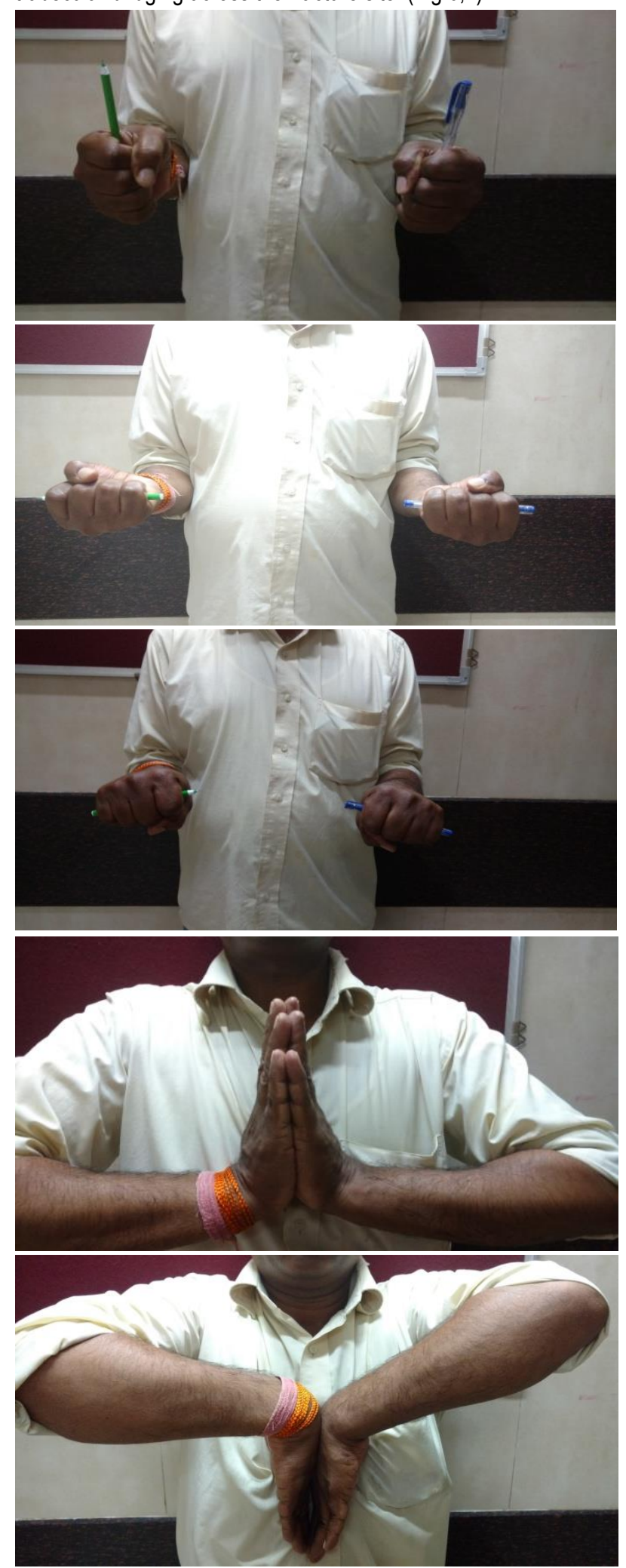

Fig 8-12: Showing clinical images of 6 month follow-up of a 32 year old male operated on left side lower radius fracture showing full range of motion at wrist

\section{Cinical Evaluation}

Patient was clinically evaluated at 3 months and 6 months for Hypertrophic Scars, Pain, Mean Palmer Flexion, mean dorsiflexion, mean pronation, mean supination with a goniometre, deformity, Clinican outcome base on gartland and werley score (Fig 8-12)

\section{Statistical Analysis}

Continuous variables were described using means and standard deviations with ranges. Statistical analyses were performed using Student's $t$ test and multivariate analysis of variance (MANOVA). $P$ values of $\leq 0.05$ were considered significant.

\section{RESULTS}

From a study population of 25 patients with a mean age of 49,18 patients $(72 \%)$ has involvement in dominant side, 20 patients have fractures in right side and 5 patients in left side.

Radiographic evaluation: All fractures united at the three months follow-up. At the 6 month follow-up, there was a mean of $17^{\circ}$ of radial inclination, 2.5-mm radial shortening, no articular incongruity and a mean volar tilt of $3.4^{\circ}$. The radial inclination and volar tilt did not show any significant change from surgery to final follow-up. There was an increase in radial shortening between the surgery and the 6 month follow up. Articular congruity with less than 2-mm articular step-off was seen in the post-operative radiographs in 16 of 19 type $B$ and $C$ fractures and less than 1-mm articular gap in 10 of 19 type B and C fractures. No extra-articular (type A) fractures showed any articular incongruity in the immediate postoperative and follow-up radiographs.

Clinical evaluation: At the final follow-up, the mean range of wrist motion consisted of $82 \pm 6$ degrees of pronation, $83 \pm 4$ degrees of supination, $68 \pm 7$ degrees of dorsiflexion, $59 \pm 13$ degrees of volarflexion, $14 \pm 5$ degrees of radial deviation, and $29 \pm 6$ degrees of ulnar deviation. All patients were able to return to domestic duties or to their occupations when examined at the one year follow-up. According to the score of Garland and Werley, $20(80 \%)$ patients had excellent results and $3(12 \%)$ had good results. Age affected the functional outcome of fixation, i.e. Garland and Werley score was worse with increasing age $(p<0.01) .3$ of 25 i.e. $12 \%$ patients developed hypertrophic scars with slight contracture, which show it to be significant. These contractures were relieved by final follow-up due to vigorous physical rehabilitation

Complications: None of the patients reported with complications like median nerve palsies, Carpal tunnel syndrome, tendon irritation, 3 out of 25 patients had hypertrophic scars.(Fig 13)

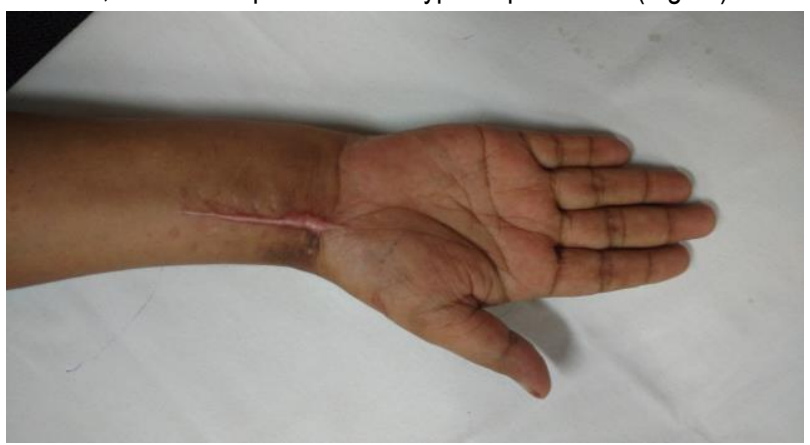

Fig 13: 26 year old female at 3 months follow-up showing hypertrophic scar at the operative site on right side 


\section{DISCUSSION}

The importance of restoring the anatomical alignment and articular congruity is well recognized in the fixation of distal radial fractures. Intra-articular incongruity has been shown to correlate with posttraumatic arthritis, ${ }^{9}$ whilst malalignment can lead to decreased grip strength, reduced range of motion and instability. ${ }^{1}$ Internal fixation results in a better restoration and preservation of radial length and volar tilt compared with external fixation. ${ }^{10}$ The advent of the locking plate system provides a more secure and reliable fixation for osteoporotic bones.

The smaller implants have been designed to address the increasingly complex fracture patterns encountered in osteoporotic bones, fracture fragments can be addressed individually. The smaller profile plates allow a more distal placement, hence a more subchondral fixation, with less tendon and soft tissue irritation. The smaller T- and straight plates permit a fragment-specific approach in accordance with the three-column theory in distal radius fracture fixation

Three radiographic measurements are accepted in the anatomical evaluation of the distal end of the radius, ${ }^{11}$ All three are recorded in relationship to the longitudinal axis of the radius. On the lateral radiograph, the palmer slope of the distal end of the radius averages 11 to 12 degrees. ${ }^{12}$ Radial inclination is measured on the antero-posterior radiograph and is represented by the angle formed by a line drawn from the tip of the radial styloid process to the ulnar corner of the articular surface of the distal end of the radius and a line drawn perpendicular to the longitudinal axis of the radius. The average radial inclination is 22 to 23 degrees $32 .{ }^{\prime}{ }^{12}$ Radial length, also measured on the antero-posterior radiograph, is represented by the distance between the two perpendiculars to the long axis of the radius, one at the tip of the radial styloid process and the other at the distal articular surface of the ulnar head. ${ }^{13}$ The normal length of the radius averages $11 \mathrm{~mm}$ to $12 \mathrm{~mm}$. Our series demonstrated there was no significant difference in the radial length and volar tilt comparing radiographs immediately following operation with those at final follow-up. Hence the radiographic reduction achieved post-operatively can be effectively maintained over time with this method of fixation. These results are comparable with other published studies using volar plating of distal radial fractures. ${ }^{14-16}$

Table 1: Comparison between our study conducted in a tertiary centre in India and some of the recent relevant studies.

\begin{tabular}{lcccc}
\hline & $\begin{array}{c}\text { Radial } \\
\text { Inclination }\end{array}$ & $\begin{array}{c}\text { Radial } \\
\text { shortening }\end{array}$ & Palmar tilt & $\begin{array}{c}\text { Garland and Werley (Good } \\
\text { and excellent results ) }\end{array}$ \\
\hline Our Study & $17.5^{\circ}$ & $2.5 \mathrm{~mm}$ & $3.4^{\circ}$ & $92 \%$ \\
Kenny Kwan et al ${ }^{16}$ & $18^{\circ}$ & $1.3 \mathrm{~mm}$ & $5^{\circ}$ & $98 \%$ \\
Arora et al ${ }^{14}$ & $19.8^{\circ}$ & & $1^{\circ}$ & \\
Denju Osada et al ${ }^{15}$ & $22^{\circ}$ & & $9^{\circ}$ & $100 \%$ \\
\hline
\end{tabular}

Both the Gartland and Werley and score demonstrated that the overall physician-rated functional outcomes were satisfactory. All movements of the wrist and forearm, and the grip strength reached an excellent level according to the Gartland and Werley score.

Cooney et al. reported a rate of complications of more than 31 per cent; the complications included dysfunction of the median nerve, malposition, arthritis of the radiocarpal or radio-ulnar joint, stiffness of the digits, rupture of a tendon, causalgia, and even Volkmann ischemic contracture. ${ }^{17}$ Dysfunction of the median nerve has been the most frequent complication in most series. ${ }^{18}$ As opposed to this, our study shows no median nerves dysfunctions, though 3 out of 25 patients reported hypertrophic scars.

When the range of motion was analyzed according to age, there was a trend that the elderly patients seemed to regain less motion. This was reflected in the Garland and Werley score, which were scoring systems done by mainly objective evaluations.

\section{CONCLUSION}

The strength of our study is that all procedures were performed in a single centre by or under the supervision of one experienced surgeon; thus, the principle and concept of fixation were consistent. The follow-up evaluations were also conducted with the same group of surgeons and physiotherapists. In addition, we obtained a good follow-up rate. Overall, we believe this study has demonstrated a good clinical outcome with no loss of radiographic reduction using the locking plate system in the fixation of distal radial fractures, no median nerve palsy, no tendonitis, with good clinical outcome and good patient satisfaction. However, a prospective randomized controlled trial is required to resolve whether this system of internal fixation is superior to other treatment modalities.

\section{REFERENCES}

1. Neal C. Chen, MD; Jupiter JB, MD : Current Concepts Review, Management Of Distal radial fractures. J Bone Joint Surg Am. 2007; 89:2051-62.

2. Robert W. Bucholz, MD, James D Heckman, MD: Rockwood Greens Fractures in Adults. 5th edition, Lippincott Williams \& Wilkins 2001 Volume I: $815-867$.

3. Bartosh RA, Saldana MJ. Intrarticular fractures of the distal radius: a cadaveric study to determine if ligamentotaxis restores radiopalmar tilt. J Hand Surg [Am] 1990; 15(1):18-21.

4. Rikli DA, Regazzoni $P$. Fractures of the distal end of the radius treated by internal fixation and early function. A preliminary report of 20 cases. J Bone Joint Surg Br 1996; 78(4):588-92.

5. Muller ME, Nazarian S, Koch $P$, Schatzker J. The comprehensive classification of fractures of long bones. New York: Springer-Verlag; 1990. (Accessed September 01, 2016)

Available from: https://www2.aofoundation.org

6. Hardy DH, Totty G, Renuis WR et al: Posterioanterior wrist radiography: Importance of arm positioning. J. Hand Surg 12A;504,1987.

7. Martineau PA, Berry GK, Harvey EJ. Plating for Distal Radius Fractures. Orthopedic Clinics of North America. Orthop. Clin. N. Am., 2007, 38: 193-201.

8. Kreder H J, Hanel D P, Mckee M, Jupiter L, Mc Gillivary G, 
Swiontkowski MF. X-ray film measurements for healed distal radius fractures. J Hand Surg Am. 1996; 21(1):31-39. DOI: 10.1016/S0363-5023(96)80151-1.

9. Baker SP, O'Neill B, Haddon W, Jr, Long WB. The injury severity score: a method for describing patients with multiple injuries and evaluating emergency care. J Traumatol.1974; 14:187-196.

10. Leung F, Tu YK, Chew WY, Chow SP. Comparison of external and percutaneous pin fixation with plate fixation for intra-articular distal radial fractures. A randomised study. J Bone Jt Surg Am. 2008; 90(1):16-22. DOI: 10.2106/JBJS.F.01581.

11. Dowling J. J., And Sawyer, Backwell, Comminuted Colles Fractures. Evaluation of a Method of Treatment. J. Bone and Joint Surg. 43A: 657-668, July 1961.

12. Fribergs, Seven, and Lundstrom, BO: Radiographic Measurements of the Radio-Carpal Joint in Normal Adults. Acta Radiol. Diag., 17:249-256, 1976.

13. Gartland J.J., Jr., And Werley, C.W.: Evaluation of Healed Colles Fractures. J. Bone and Joint Surg., 33-A: 895-907, Oct. 1951.

14. Arora R, Lutz M, Fritz D, Zimmermann R, Oberladstätter J, Gabl M. Palmar locking plate for treatment of unstable dorsal dislocated distal radius fractures. Arch Orthop Trauma Surg. 2005; 125(6):399-404. DOI: 10.1007/s00402-005-0820-8.

15. Osada D, Kamei S, Masuzaki K, Takai M, Kameda M, Tamai K. Prospective study of distal radius fractures treated with a volar locking plate system. J Hand Surg Am. 2008; 33(5):691-700. DOI: 10.1016/j.jhsa.2008.01.024.
16. Kwan K, Lau TW, Leung F. Operative treatment of distal radial fractures with locking plate system-a prospective study. International Orthopaedics. 2011; 35(3): 389- 394. DOI: 10.1007/s00264-010-0974-z.

17. Cooney W.P.,III; Dobyns J.H.; Linscheid R. L: Complications of Colles' Fractures. J. Bone and Joint Surg., 62-A:613-619, June1980.

18. Frykman, Gosta: Fracture of the Distal Radius Including Sequelae -- Shoulder-Hand-Finger Syndrome, Disturbance in the Distal Radio-Ulnar Joint and Impairment of Nerve Function. A Clinical and Experimental Study. Acta Orthop. Scandinavica, Supplemantum108, 1967.

\section{Source of Support: Nil. Conflict of Interest: None Declared.}

Copyright: (c) the author(s) and publisher. IJMRP is an official publication of Ibn Sina Academy of Medieval Medicine \& Sciences, registered in 2001 under Indian Trusts Act, 1882.

This is an open access article distributed under the terms of the Creative Commons Attribution Non-commercial License, which permits unrestricted non-commercial use, distribution, and reproduction in any medium, provided the original work is properly cited.

Cite this article as: Jairam Jagiasi, Ali Saify, Ankit Prasad, Amit Joshi, Vivek Dubey, Rajnikant Patel. Assessment of Functional Outcome in Distal End Radius Fractures Managed with Locking Plates. Int J Med Res Prof. 2016; 2(5):107-12. 